\title{
Numerical study on strengthening composite bridges
}

\author{
K. Narmashiri \& M.Z. Jumaat \\ University of Malaya, Kuala Lumpur, Malaysia
}

\begin{abstract}
This research examines the effects of using CFRP strips and steel plates for flexural strengthening of composite bridge. Computer simulation is used and adopted from a computer program called ANSYS. The specimens are modeled in full 3D case, thus the concrete deck, concrete reinforcements, steel profile, steel plates, shear connectors, adhesive and CFRP strips are modeled in 3D solid elements (Tetra 10 node 187). Non-linear static analysis method is used in this research. The steel profile, concrete section and girder length measurements are the same for all models. Polymer strips and steel plate's thicknesses are different for each model, though. The results are compared in stress levels on CFRP strips or steel sheets, strain on adhesive and concrete, and deflection of the bridge girder. The results indicate that stress, strain, deflection, and load bearing in different samples are affected by type of material and thicknesses.
\end{abstract}

\section{BACKGROUND}

\subsection{Introduction}

The various sorts of methods exist for strengthening different steel structures, such as putting up additional steel parts, applying steel plates, including external pre-stressing of the parts, reducing or bridging the gap between the supports, and applying Fiber Reinforced Polymer (FRP). Under normal circumstances, strengthening steel-concrete composite bridges is carried out using steel plates or CFRP sheets, but what is widely used today for this purpose is Fiber Reinforced Polymer (FRP). FRP is a composite substance treated with resin with qualities of high tension, light weight, and a high resistance to corrosion. That explains why it has been used so often for strengthening steel and concrete structures. FRP can be produced from Carbon Fiber Reinforced Polymer (CFRP) or Glass Fiber Reinforced Polymer (GFRP). However, applying (CFRP) for the mentioned purpose has proven to be more satisfactory than GFRP. High Modulus (HM) resin which results in greater resistance has been more popularly used recently. In this research, examination on the effects of applying CFRP and steel plates on the flexural strengthening composite bridge is tried. An analysis of the comparison is also done. Some samples were considered for this study. Computer simulation adopted from a computer program called ANSYS was also used. The samples are modeled in 3D case; so concrete decks, concrete reinforcements, steel profile, steel plates, shear connectors, adhesive and CFRP strips are modeled in 3D solid elements (Tetra 10 node 187). Non linear static analysis method is used in this research. The steel profile, concrete section and girder length measurements are the same for all models. Polymer strips and steel plate's thicknesses are different for each model, though. The results of strengthening composite bridge, with CFRP or steel sheets are measured as indicated by the figures in the diagrams, and they indicate the effects of strengthening the bridge girder by the mentioned methods. These results are compared based on the stress exerted on CFRP or steel sheets, and the strain on the adhesive and concrete, and the deflection of the bridge girder.

\subsection{Literature review}

Recently, applying FRP for strengthening structures has become more popular because other strengthening methods have limitations especially for structures that are under loading.

Strengthening steel-concrete bridges have been researched by some scientists. Edberg et al. (1996) studied the application of CFRP for strengthening steel girders. An efficient way of strengthening the girder has also been found by Gillespie et al. (1996.) The strengthening of girders regarding the corrosion effects and section reduction was examined by Liu et al. (2001) \& Tavakolizadeh et al. (2001, 2003.) Strengthening steel-concrete composite bridge girders using carbon polymer was examined too by Sen et al. (2001) and Tavakolizadeh et al. (2001, 2003.) Also, applying high modulus carbon polymer in order to strengthen the steel-concrete composite bridge girder was examined by Schnerch et al. $(2004,2006$, and 2007) and Dawood et al. (2006.) For the abovementioned studies though, longitudinal sheets were used for the strengthening process. The abovementioned researches showed that before the maximum tension strength level was reached, a state of debonding occurred on the longitudinal polymer sheets. 
The effects of CFRP cutting shape on steel-concrete composites were also looked into by Schnerch et al. (2004, 2006, and 2007). The findings were further reinforced by Narmashiri et al. (2009), especially in the effects of end cutting shape of HM-CFRP on the stress and strain intensity. The effects of 2D and 3D computer simulation of strengthened steel-concrete bridges on stress, strain, and deflection for different parts of the girder were examined by M.Z. Jumaat et al. (2009.)

In this research comparison between the application CFRP sheets and steel plates for strengthening steelconcrete composite bridges were examined, and the results present a better understanding of the effects of applying steel plates or CFRP sheets on the different parts of the girder.

\section{MODELING}

\subsection{Computer simulation method}

Finite element method by ANSYS program is used for simulation and analysis of the samples. The samples are modeled in 3D case, and concrete deck, concrete reinforcements, steel profile, steel plates, shear connectors, adhesive and CFRP strips are modeled in 3D solid elements (Tetra 10 node 187). Non linear static analysis method is used in this research.

\subsection{Specification of the samples}

Specifications of the samples are shown in Figures 1-4. The maximum value of the load $\mathrm{P}$ is $200 \mathrm{KN}$ ( 2 point load $100 \mathrm{KN}$ ) which is applied to the structure step by step using the nonlinear analysis method.

The length of the girder is $3000 \mathrm{~mm}$, and the length of constant moment region is $800 \mathrm{~mm}$. The length of CFRP sheet or steel plates are $2000 \mathrm{~mm}$, and their widths are $50 \mathrm{~mm}$. CFRP thicknesses are 1.4 or $2 \mathrm{~mm}$, and the elasticity modulus is $300 \mathrm{MPa}$. The steel plate thicknesses are 6 or $8 \mathrm{~mm}$, and the elasticity modulus is $210 \mathrm{MPa}$. The steel section is U152*152*30. The steel section and steel plates have the same material

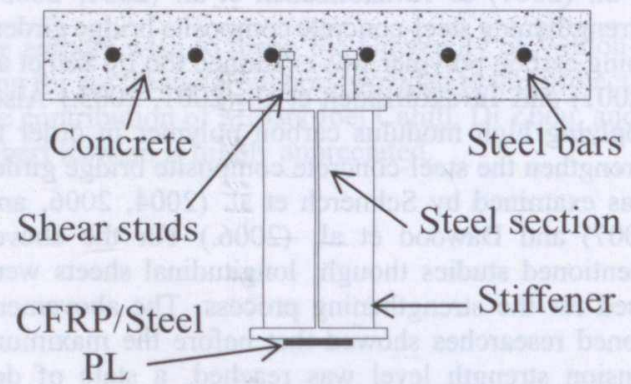

Figure 1. Specifications of the girder.

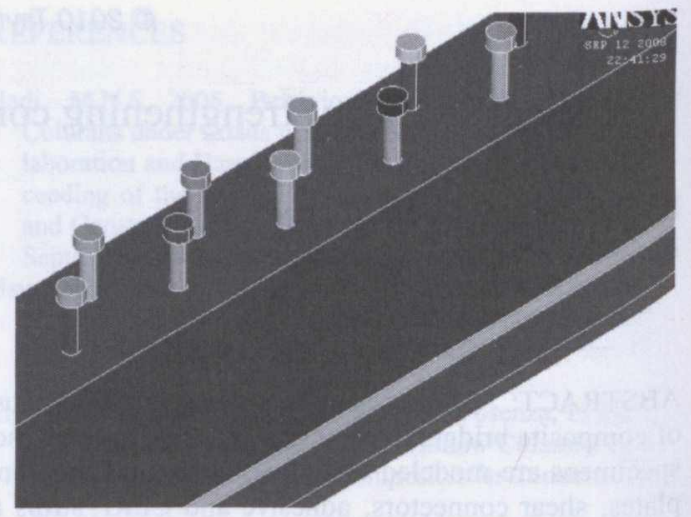

Figure 2. Shear connector location.

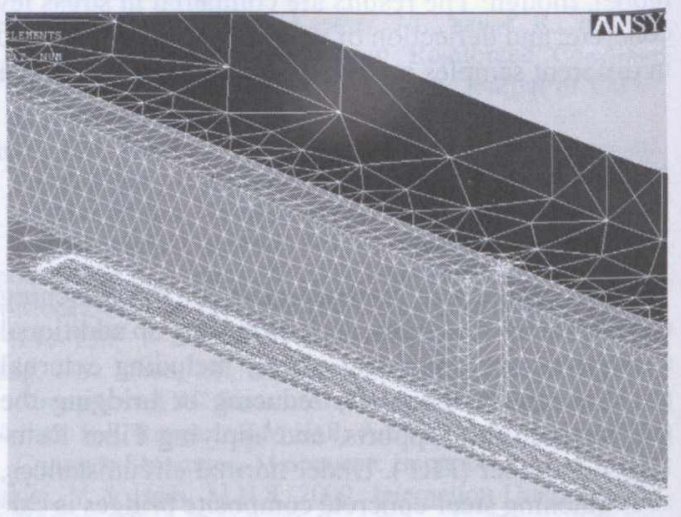

Figure 3. Strengthened sample by CFRP/Steel plate.

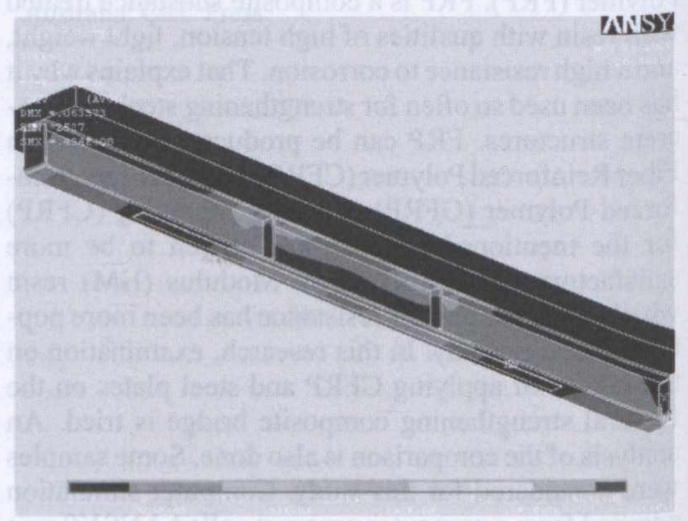

Figure 4. Three dimensional simulated sample.

of low carbon. The shear studs diameter is $10 \mathrm{~mm}$ with length $50 \mathrm{~mm}$, and their distances are $100 \mathrm{~mm}$. The compression strength of concrete for the deck is $25 \mathrm{MPa}$. The deck width is $400 \mathrm{~mm}$, and the thickness is $70 \mathrm{~mm}$. The steel bar diameter is $10 \mathrm{~mm}$ and it is 
of the same grade as the steel section and steel plates, and the distance of bars is between 75 to $100 \mathrm{~mm}$. CFRP sheets and steel plates were pasted onto the bottom of steel section flanges by adhesive. It is noted that CFRP and steel plates do not have the same thicknesses. Steel plate thickness is more than that of the CFRP sheet, because in actual applications, the steel plates are thicker than CFRP sheets.

\section{NUMERICAL ANALYSIS}

\subsection{Stress on CFRP or steel plate}

In this section the effects of strengthening composite bridge girder with CFRP or steel plate on the maximum Von Mises stress of CFRP and steel plate are examined.

Von Mises stress on different parts of the girder is shown in Figure 5. This figure shows the maximum Von Mises stress on CFRP or steel plates appears in the pure bending region especially under the point load at mid span. The effects of application CFRP sheets or steel plates on the maximum stress of them are shown in Figure 6. In this figure, the horizontal axis is the load that is increasingly applied to the structure using the nonlinear analysis method. The vertical axis indicates the maximum Von Mises stress on CFRP sheet or steel plate. The maximum Von Mises stress is located in the pure bending region. Figure 6 shows that in the primary steps of loading there is no difference between applying CFRP or steel plate with different thicknesses, but with increasing load, greater stress appears on the steel plates than on CFRP sheets.

Also, the best stress result (lowest) appears on CFRP with the greater thickness, and the load bearing capacity of CFRP sheets is also better than steel plates.

\subsection{Strain on adhesive}

In this section the effects of the application CFRP sheets or steel plates on the Maximum shear strain on the adhesive are examined.

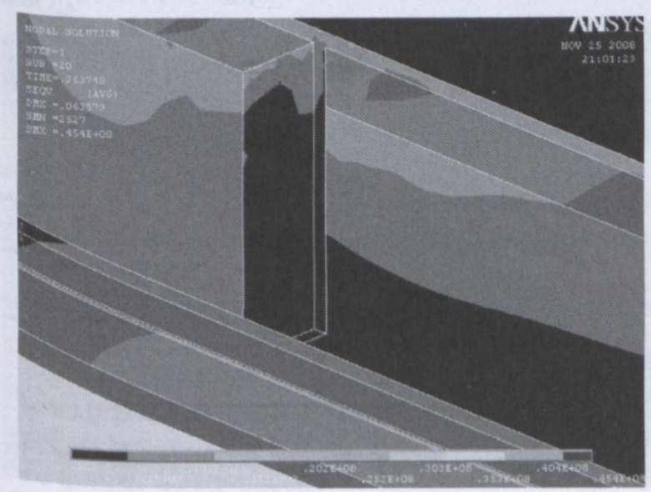

Figure 5. Von Mises stress for different parts of the girder.

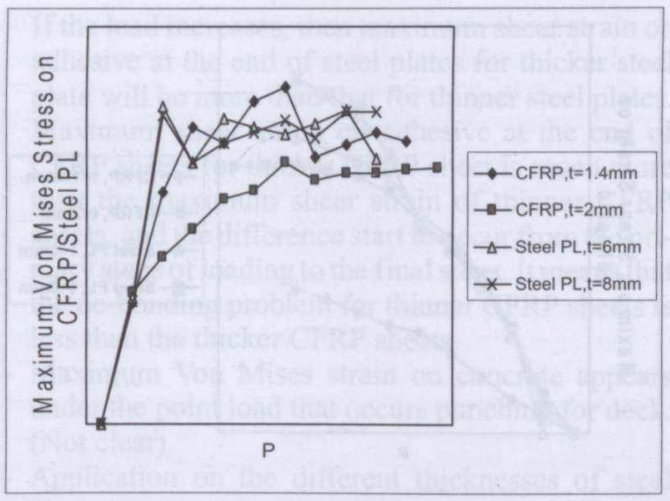

Figure 6. Maximum Von Mises stress on CFRP or steel plate.

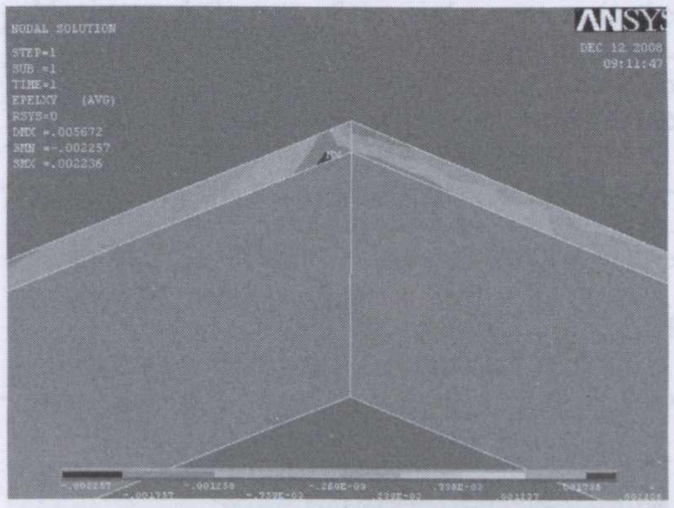

Figure 7. Shear strain on adhesive at the end of CFRP or steel plate.

Figure 7 shows the maximum shear strain on the adhesive appears at the end of CFRP sheet or steel plate, and this problem gives rise and may have caused the de-bonding of CFRP sheets or steel plates in the pasted regions. Figure 8 shows the effects of the application CFRP sheets or steel plates on the maximum shear strain of adhesive. In Figure 8, the horizontal axis represents the load, and the vertical axis is the maximum shear strain on adhesive at the end of CFRP sheet or steel plate. It shows that at the primary steps of loading, the shear strain on the adhesive for steel plates with different thicknesses are the same, but after increasingly heavier loads, the shear strain on adhesive for the thicker steel plate is greater than thinner ones. Also, shear strain on the adhesive for thicker CFRP sheets is closer to the shear strain on the adhesive for the steel plates, but for the thinner CFRP sheets, shear strain on the adhesive is so much less than the thicker CFRP sheets or steel plates, and this difference for primary and final steps of loading are important. It means 


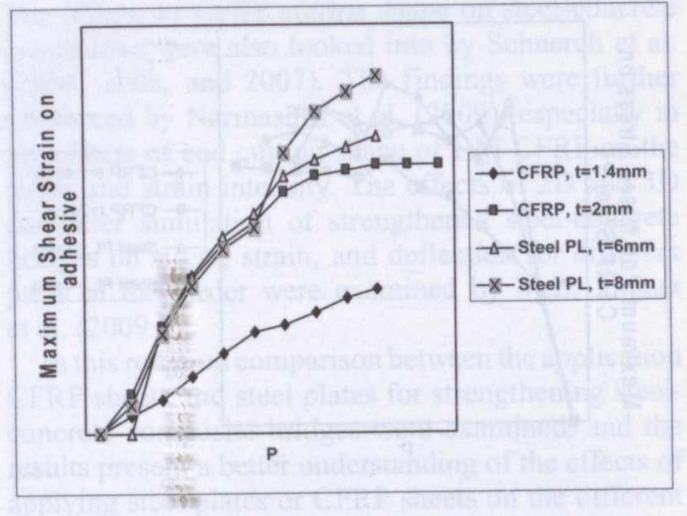

Figure 8. Maximum shear strain on adhesive at the end of CFRP or steel plate.

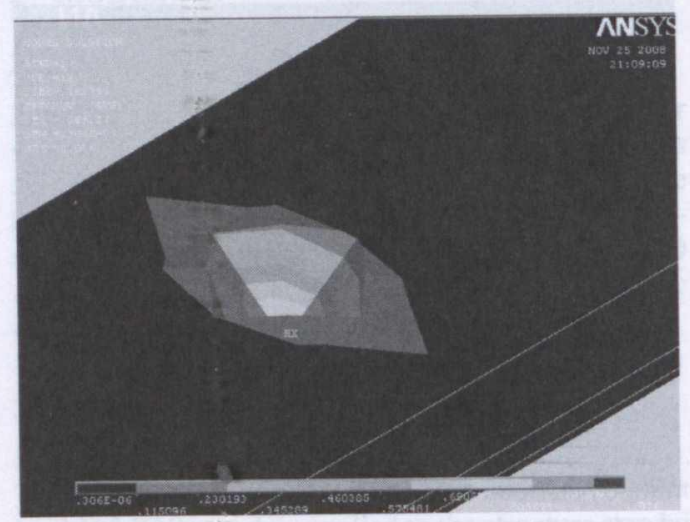

Figure 9. Punching of concrete under the point load.

application of thinner CFRP sheets to overcome the debonding problem is better than thicker CFRP sheets or steel plates. Also, this figure shows the load bearing capacity of thicker CFRP is better than the steel sheets.

\subsection{Strain on concrete}

In this section the effects of the application CFRP sheets or steel plates on the maximum Von Mises strain of concrete are examined.

Figure 9 shows that large deformation appears under the point load region, and it punches the deck caused by point loads.

The effects of application CFRP sheets or steel plates on the maximum Von Mises strain of concrete are shown in Figure 10. In this figure, the horizontal axis represents the load, and the vertical axis represents the maximum Von Mises strain on concrete at the point loading region. Figure 10 shows that the results for steel plate strengthening with varying plate thicknesses and CFRP sheet strengthening using maximum Von Mises strain are the same, but maximum Von Mises strain on concrete for thinner CFRP strengths is greater than in other cases. Also, the load bearing CFRP sheets has a better capacity than steel plates.

\subsection{Deflection of the girder}

One of the most important parameters for strengthening structures is deflection and how to control it. In this section the effects of application CFRP sheets or steel plates on the maximum deflection of the girder are examined.

Figure 11 shows the maximum deflection of the girder in the pure bending region and at the middle of the span.

Figure 12 tabulates the effects of the application of CFRP sheets and steel plates on the maximum deflection of the girder. In this figure the horizontal axis represents the applied load, and the vertical axis represents the maximum deflection of the girder at the

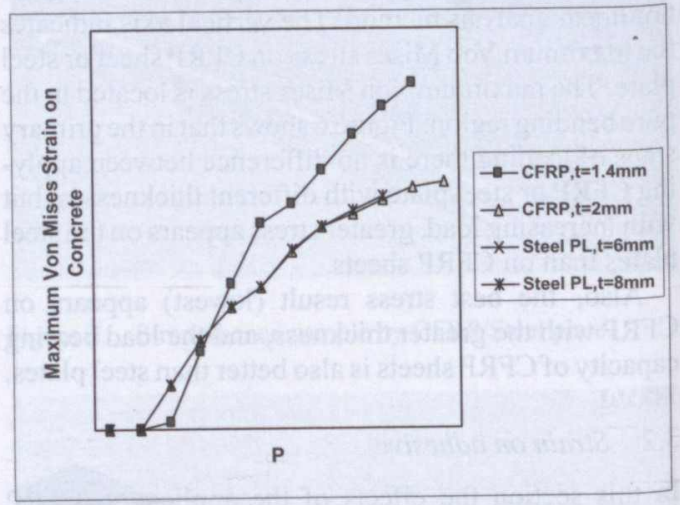

Figure 10. Maximum Von Mises strain on concrete.

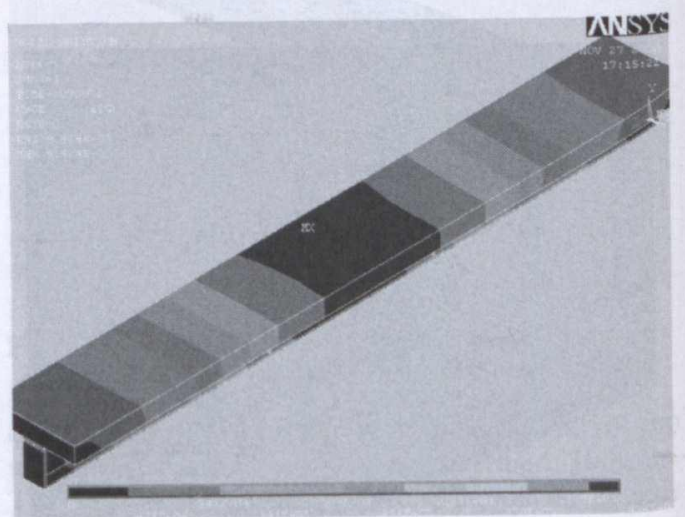

Figure 11. Deflection of the girder. 


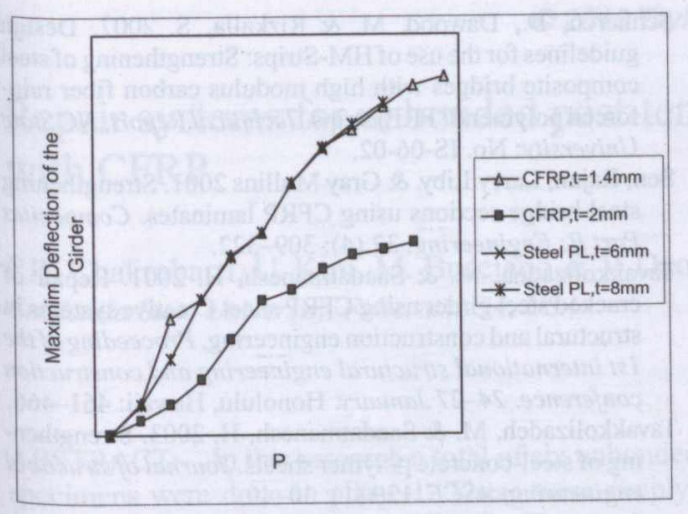

Figure 12. Maximum deflection of the girder at the middle of span.

mid span. This figure shows for steel plate strengthening case with different thickness of plate the maximum deflection of the girder is so close to each other. Also, the maximum deflection of the girder in CFRP strengthening case with thinner CFRP is closer to the steel plate readings, but for the thicker CFRP strengthening case the maximum deflection of the girder is less than that of the steel plates. Also, load bearing CFRP sheets is more than steel plates.

\section{CONCLUSIONS}

In review on the abovementioned highlights, figures, and graphs, some conclusions can be made:

- Maximum Von Mises stress on CFRP sheet or steel plate at the pure bending region.

- In the primary steps of loading Von Mises stress on CFRP sheets or steel plates with different thicknesses are the same.

- If the load increases, then Von Mises stress on steel plates will be greater than CFRP sheets.

- The different thicknesses of steel plates have no noticeable effects on the Von Mises stress of steel plates.

- If the thicker CFRP sheets are chosen, then Von Mises stress on CFRP sheets are much lesser than thinner CFRP sheets.

- Maximum shear strain on the adhesive appears at the end of CFRP sheets or steel plates and may result in de-bonding, and it seems not to let CFRP sheets or steel plates bear the load up to their final capacity. It seems better to use thicker adhesive for steel plates or thinner CFRP sheets.

- Maximum shear strain on adhesive at the end of steel plates for different thicknesses is the same.
- If the load increases, then maximum shear strain on adhesive at the end of steel plates for thicker steel plate will be more than that for thinner steel plates.

- Maximum shear strain on adhesive at the end of CFRP sheets for thicker CFRP sheet is much more than the maximum shear strain of thinner CFRP sheets, and the difference start to occur from the primary steps of loading to the final steps. It means that the de-bonding problem for thinner CFRP sheets is less than the thicker CFRP sheets.

- Maximum Von Mises strain on concrete appears under the point load that occurs punching for deck. (Not clear)

- Application on the different thicknesses of steel plates has no noticeable effects on Von Mises strain on concrete.

- If the thickness of CFRP is less, then there is more strain on the concrete.

- Maximum deflection of the girder appears in the pure bending region which located in the mid span.

- The different thicknesses for steel plates have no noticeable effects on the maximum deflection of the girder.

- If thicker CFRP sheets are chosen, then the maximum deflection of the girder will be less noticeable.

- Load bearing CFRP sheet is better than steel plate in rehabilitation.

- Load bearing CFRP sheet is much greater than steel plate with the same thickness.

- Load bearing of thicker CFRP sheets is greater than thinner CFRP sheets.

\section{REFERENCES}

Dawood, M., Sumner, E. \& Rizkalla, S. 2006. Fundamental Characteristics of High Modulus CFRP Materials for Strengthening of Steel-Concrete Composite Beams. Proceedings for Structural Faults \& Repair, 13-15 June 2006. Edinburgh: Scotland: CD-ROM.

Edberg, W., Dennis, M. \& John Gillespie, Jr. 1996. Rehabilitation of steel beams using composite materials, Material for the new millennium. Proceeding of the ASCE fourth materials engineering conference. 10-14 November 1996. Washington, D.C: $502-508$.

Gillespie, J.W., D.R. Mertz, K. Kasai, W.M. Edberg, J.R. Demitz \& I. Hodgson 1996. Rehabilitation of steel bridge girder: Large scale testing. Proceeding of the American society for composites 11th technical conference. 4-7 November 1996. Atlanta, Georgia: 1249-1257.

Jumaat, M. Z. \& Narmashiri, K. 2009. Compare between 2D and $3 \mathrm{D}$ computer modeling for strengthening composite steel-concrete bridges with HM-CFRP and steel sheets. Proceedings of 9 th international conference on steel concrete composite and hybrid structures. 8-10 July 2009. Leeds, UK: (in press.)

Liu, X., P.F. Silva \& A. Nanni 2001. Rehabilitation of steel bridge member with FRP composite materials. Proceeding of the international conference on composites in construction. 10-12 October 2001: 613-617. 
Narmashiri, K. \& Jumaat, M.Z. 2009. Effect of the HMCFRP sheets cutting shape on the stress and strain intensity of strengthened composite bridges. Proceedings of 2nd international conference on Geo-Information Technology for Natural Disaster Management and Rehabilitation. 30-31 January 2009. Bangkok, Thailand: 156-160.

Schnerch, D. \& Rizkalla, S. 2004. Behavior of scaled SteelConcrete composite girders and steel Monopole Towers strengthened with CFRP. Proceedings of the Innovative Materials and Technologies for Construction and Restoration conference (IMTCR). 6-9 June 2004. Leece, Italy: 42-60.

Schnerch, D., Dawood, M., Sumner, E. \& Rizkalla, S. 2006. Design guidelines for Strengthening of Steel-Concrete Composite Beams with High Modulus CFRP Materials. Proceedings of the 7th International Conference on Short and Medium Span Bridges. 23-25 August 2006. Montreal, Quebec, Caǹada: CD-ROM.
Schnerch, D., Dawood, M. \& Rizkalla, S. 2007. Design guidelines for the use of HM-Strips: Strengthening of steel composite bridges with high modulus carbon fiber reinforced polymer (CFRP) strips. Technical Report, NC State University: No. IS-06-02.

Sen, Rajan, Larry Liby. \& Gray Mullins 2001. Strengthening steel bridge sections using CFRP laminates. Composites Part B: Engineering. 32 (4): 309-322.

Tavakkolizadeh, M. \& Saadatmanesh, H. 2001. Repair of cracked steel girder using CFRP sheet Creative systems in structural and construction engineering. Proceeding of the 1st international structural engineering and construction conference. 24-27 January. Honolulu, Hawaii: 461-466.

Tavakkolizadeh, M. \& Saadatmanesh, H. 2003. Strengthening of steel-concrete polymer sheets. Journal of structural engineering, ASCE. 129 (1): 30-40. 